\title{
The Clinical Course of Patients with Idiopathic Epiretinal Membranes and Good Visual Acuity Managed Without Surgery
}

This article was published in the following Dove Press journal: Clinical Ophthalmology

\author{
Eduardo F Damasceno ${ }^{1,2}$ \\ Nadyr A Damasceno ${ }^{1,3}$ \\ Ashley M Crane' \\ Nicolas A Yannuzzi' \\ Nidhi Relhan' \\ William E Smiddy (D) \\ Harry W Flynn'
}

'Department of Ophthalmology, Bascom Palmer Eye Institute, University of Miami, Miller School of Medicine, FL, USA; ${ }^{2}$ Department of Ophthalmology, Universidade Federal Fluminense, Niteroi, RJ, Brazil; ${ }^{3}$ Department of Ophthalmology, Hospital Naval Marcilio Dias, Rio de Janeiro, RJ, Brazil
Correspondence: Harry W Flynn Department of Ophthalmology, Bascom Palmer Eye Institute, University of Miami, Miller School of Medicine, 900 N.W. 17th Street, Miami, Florida 33136, USA

Tel $+|-305-326-6| 18$

Fax+1-305-326-64I7

Email HFlynn@med.miami.edu
Background/aims: To report the clinical course of patients with idiopathic epiretinal membranes (iERMs) and good baseline best-corrected visual acuity (BCVA) managed without surgical treatment.

Methods: Retrospective, observational case series of patients with iERMs and 20/50 or better BCVA who did not undergo surgery between January 2014 and December 2017 with a 1-year follow-up. Secondary epiretinal membranes were excluded. iERMs were stratified into two groups: Group I (BCVA 20/30 or better) and Group II (BCVA 20/40 to 20/50). The main outcome measures included baseline and final follow-up BCVA, central macular thickness (CMT) on OCT.

Results: The study included 174 eyes (145 patients): 139 eyes (79.8\%) had typical iERMs and 35 eyes (18\%) had LMH. For Group I typical iERMs, the logMAR baseline and final mean BCVA were $0.09 \pm 0.1$ (Snellen equivalent 20/25) and $0.10 \pm 0.1\left(20 / 25^{+}\right)$respectively $(p=0.22)$. In this group, the baseline and final mean CMT were $335 \pm 73 \mu \mathrm{m}$ and $342 \pm 78 \mu \mathrm{m}$, respectively $(\mathrm{p}=0.47)$. For Group II typical iERMs, the logMAR baseline and final mean BCVA were $0.3 \pm$ $0.1(20 / 44)$ and $0.4 \pm 0.2(20 / 45)$ respectively $(p=0.31)$. In this group, the baseline and final mean CMT were $386 \pm 95 \mu \mathrm{m}$ and $391 \pm 93 \mu \mathrm{m}$, respectively $(\mathrm{p}=0.84)$.

Conclusion: The clinical course of patients with iERM and good baseline BCVA is generally favorable without surgery and includes stable BCVA and OCT measurements after at least one year.

Keywords: epiretinal membrane, pars plana vitrectomy, optical coherence tomography

\section{Introduction}

Idiopathic epiretinal membranes (iERMs) are defined by the spontaneous formation of fibrocellular membranes on the macular surface, resulting in a variable degree of distortion. ${ }^{1}$ The reported prevalence ranges between $8.9 \%$ in a study with 22,406 participants aged 40 to 69 and $28.9 \%$ in a study with 5960 participants aged 45 to 84 and increases with aging. ${ }^{2,3}$ The difference is likely related to diagnostic criteria and imaging technique. In the United States, approximately 30 million adults aged 43-86 are affected. ${ }^{4}$

While surgical intervention is generally safe and offers variable degrees of visual improvement, the decision for vitrectomy and membrane peel is based on multiple factors including reduced best-corrected visual acuity (BCVA), functionally significant metamorphopsia judged to be commensurate with the iERM on clinical examination and OCT features, and increased difficulties in activities of 
daily living due to visual symptoms. The potential risks and benefits of the surgical procedure are considered for each patient. ${ }^{5}$ Several studies have reported an increase of more than two Snellen lines in BCVA after surgery with iERM peeling, but the quantity of visual improvement is related to the baseline level of visual acuity. ${ }^{6}$ Some studies have reported the results of vitrectomy for patients with baseline BCVA of 20/50 or better, understandably finding better visual acuity outcomes. ${ }^{7}$ Furthermore, patients with iERMs may not have worsening visual symptoms.

The purpose of the current study is to report the clinical course of patients with iERMs and baseline BCVA of 20/ 50 or better that did not undergo pars plana vitrectomy.

\section{Methods}

The current study is a retrospective, multi-practitioner, observational case series of patients with idiopathic epiretinal membranes who did not undergo membrane peeling surgery at the Bascom Palmer Eye Institute between January 2014 and December 2017. This study complied with the Health Insurance Portability and Accountability Act (HIPAA) and was approved by the Institutional Review Board of the University of Miami Miller School of Medicine.

In the current study, an iERM was recognized by clinical examination and confirmed by spectral-domain optical coherence tomography (SD-OCT). The study inclusion criteria were patients with baseline recorded BCVA of 20/50 or better and with a minimum follow-up period of 1 year. Patients were excluded if vitrectomy was performed to remove the iERM or if there were vitreoretinal comorbidities that might be associated with secondary/induced ERM (eg secondary to retinal detachment, diabetic retinopathy, retinal vein occlusion, endophthalmitis, uveitis, trauma, high myopia, and other less common causes).

The data were collected from medical records of patients with the diagnosis of "epiretinal membrane", both idiopathic and secondary, yielding 1209 cases. Patients with secondary epiretinal membranes were excluded from the current study. The collected data included personal data (gender, ethnicity, and age), recorded baseline and final Snellen visual acuity, baseline and final lens status, and central macular thickness (CMT) measured by SD-OCT. SD-OCT was performed using either Cirrus (Carl Zeiss Meditec AG, Jena, Germany) or a Heidelberg Spectralis device (Heidelberg Engineering, Heidelberg, Germany).
Patients were stratified into two categories based on recorded BCVA. Group I eyes had BCVA of 20/30 or better, while Group II eyes had BCVA of 20/40-20/50. Visual acuities were converted into logMAR for statistical analysis. The iERMs were sub-classified as either typical iERMs or lamellar macular holes (LMH) based on OCT, according to the examples in the Preferred Practice Pattern (PPP) for Epiretinal Membranes. ${ }^{4}$

Typical iERMs were defined as membranes found on the surface of the neurosensory retina, comprised of cellular, fibrotic, and vitreous elements (Figures 1-2). ${ }^{8,9}$ These included iERMs with or without retinal thickening, superficial folds, or cystic spaces. LMHs were defined as iERMs associated with a partial thickness loss of foveal tissue (Figure 3). ${ }^{8,9}$

Statistical analysis was performed employing the software IBM-SPSS, 2015, Chicago, USA, version 23.0 IBM. The level of significance was established as $5 \%(\mathrm{p}<0.05)$. Continuous values such as age, BCVA, and CMT were expressed as mean \pm standard deviation (SD frequencies were calculated with Chi-squared tests to nominal data such as gender, race, initial and final lens status, and YAG laser capsulotomy). The Kruskal-Wallis test was used to calculate statistical significance to ordinal data such as improved and worsened BCVA and CMT (after the follow-up). Means and SD were compared with an independent two-sample $t$-test as the comparisons of the baseline and final BCVA and CMT.

\section{Results}

A total of 174 eyes of 145 patients with iERM and at least 1 year of follow-up were included in the study. As per the type of iERM, 139 eyes had typical iERMs and 35 eyes had LMH. The mean age ( \pm standard deviation) was 74.5 $( \pm 7.0)$ years for all patients with iERM, $74.5( \pm 7.2)$ years for patients with typical iERM and $74.3( \pm 6.6)$ years for patients with LMH $(\mathrm{p}=0.51)$. All patients had one or more years of follow-up as seen in Table 1.

In Group I, 70/136 (51.4\%) of patients were male, while in Group II 16/38 (42.1\%) of patients were male $(p=0.78)$. In Group I, the ethnic background of the patients was as follows: 75/136 (55.1\%) White Caucasian, 60/136 (44.1\%) Latin, and 3/136 (2.2\%) Asian, whereas in Group II, there were 25/38 (65.7\%) white Caucasian and 11/38 (28.9\%) Latin $(\mathrm{p}=0.94)$. At baseline, there were 54/136 (39.7\%) phakic and 82/136 (60.2\%) pseudophakic eyes in Group I, while Group II had $15 / 38$ (39.4\%) phakic and 27/38 (71.0\%) pseudophakic 


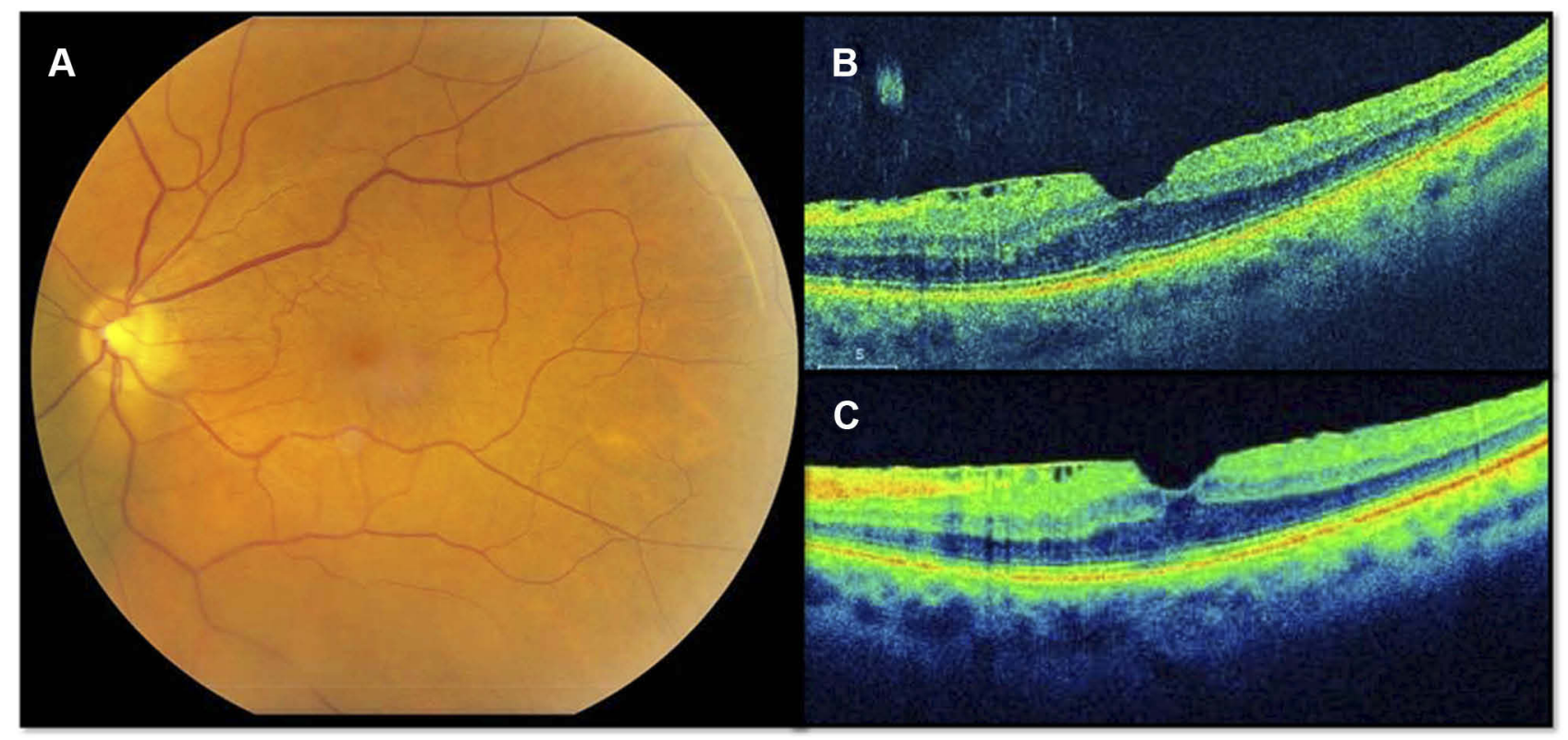

Figure I This 70-year-old male patient demonstrates a typical idiopathic epiretinal membrane with central macular involvement and minimal retinal thickening. The initial best-corrected visual acuity (BCVA) was 20/30 and the final BCVA was 20/30. (A) Fundus photograph; (B) baseline OCT image, horizontal cut; (C) final OCT image with wrinkles after 15 months of follow-up.

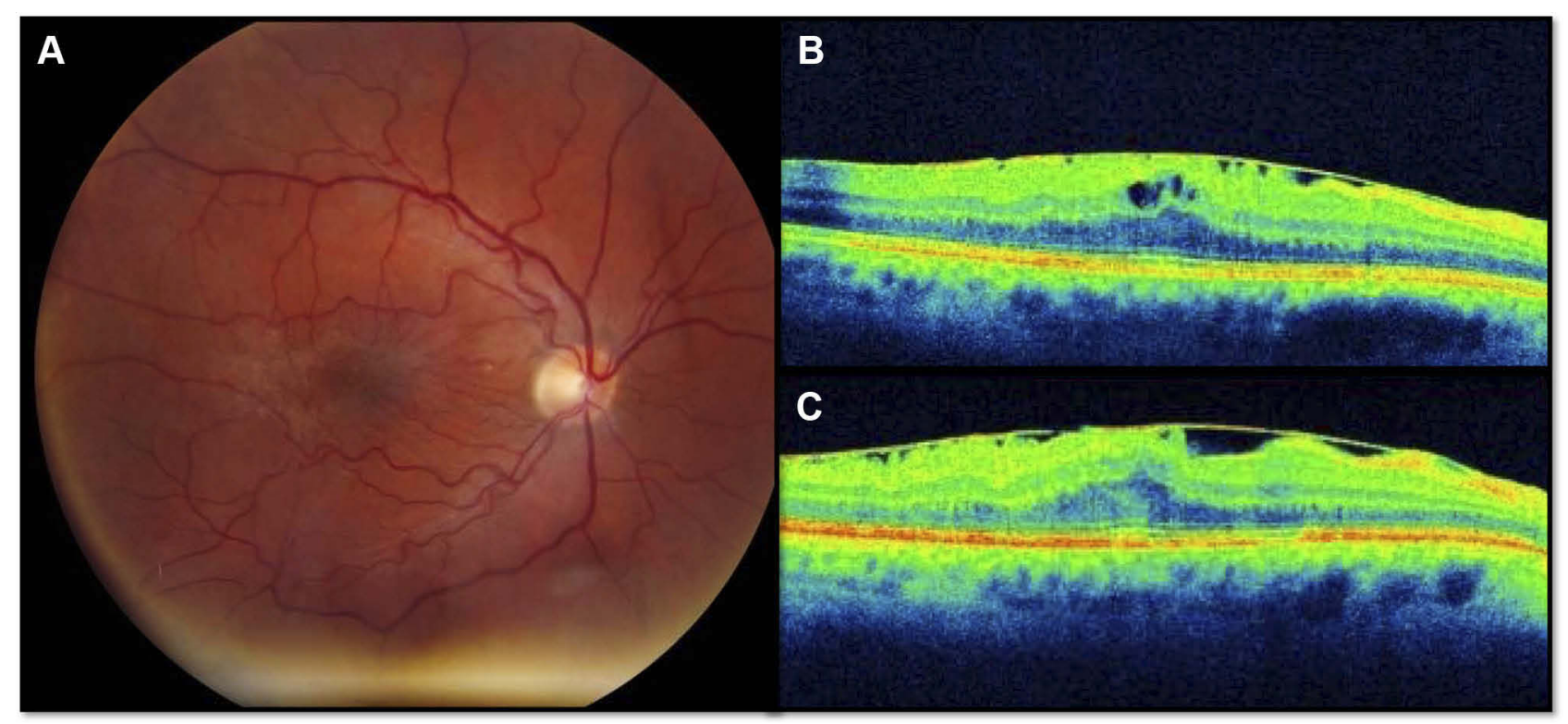

Figure 2 This 58-year-old male demonstrates a typical idiopathic epiretinal membrane with macular involvement and prominent macular thickening. The initial bestcorrected visual acuity (BCVA) was 20/40 and the final BCVA was 20/20 after cataract surgery. (A) Fundus photograph; (B) baseline OCT image, horizontal cut; (C) OCT image after 24 months of follow-up.

eyes at baseline. During the follow-up, 15/136 (11.1\%) eyes in Group I and 3/38 (7.8\%) eyes in Group II underwent cataract surgery.

At baseline, there were 136 eyes in group I (eyes with BCVA of $20 / 30$ or better) and 38 eyes in group II (eyes with BCVA of 20/40-20/50). In a follow-up of at least 1 year (Table 1), the logMAR baseline and final mean
BCVA for Group I typical iERMs were $0.1 \pm 0.1$ (Snellen equivalent 20/25) and $0.1 \pm 0.1(20 / 25)$, respectively $(\mathrm{p}=0.22)$. In this group, the baseline and final mean CMT were $335 \pm 73 \mu \mathrm{m}$ and $342 \pm 78 \mu \mathrm{m}$, respectively ( $\mathrm{p}=$ 0.47). In Group I typical iERMs, there was no statistically significant change in the BCVA and CMT between baseline and final follow-up. 


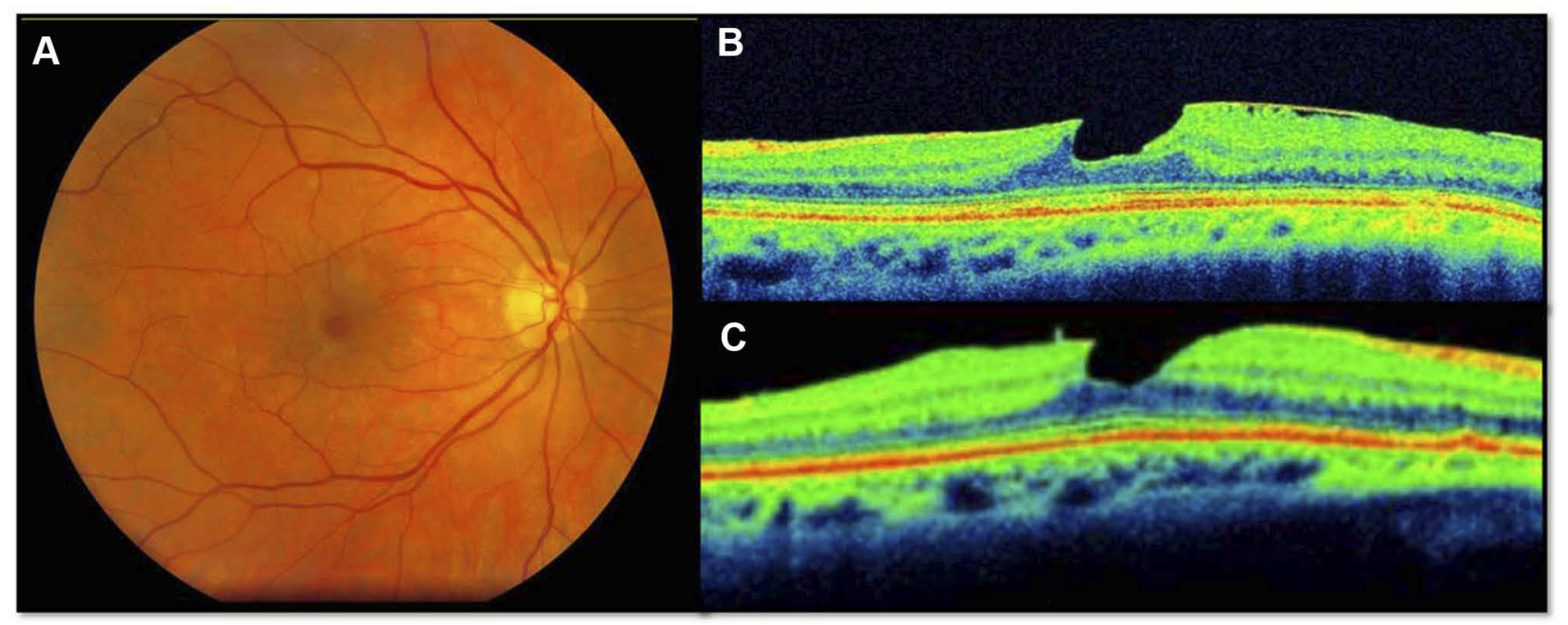

Figure 3 This 62-year-old woman demonstrates a lamellar macular hole. The baseline best-corrected visual acuity (BCVA) was 20/40 and the final BCVA was also 20/40. (A) Fundus photograph; (B) baseline OCT image; (C) OCT image after 24 months follow-up.

For Group I LMHs, the logMAR baseline and final mean BCVA were $0.1 \pm 0.1(20 / 25)$ and $0.2 \pm 0.1(20 /$ $28)$, respectively $(p=0.08)$. In this group, the baseline and final mean CMT mean were $345 \pm 73 \mu \mathrm{m}$ and $344 \pm 71 \mu \mathrm{m}$, respectively $(\mathrm{p}=0.94)$. In Group I LMHs, there was no statistically significant change in the BCVA and CMT between baseline and final follow-up.
For Group II typical iERMs, the logMAR baseline and final mean BCVA were $0.3 \pm 0.05(20 / 44)$ and $0.4 \pm 0.2$ $(20 / 45)$ respectively $(p=0.31)$. In this group, the baseline and final mean CMT were $386 \pm 95 \mu \mathrm{m}$ and $391 \pm 93 \mu \mathrm{m}$, respectively $(p=0.84)$. In Group II typical iERMs, there was no statistically significant change in the BCVA and CMT between baseline and final follow-up.

Table I Comparison of the Baseline and Final Best-Corrected Visual Acuity (BCVA) and Central Macular Thickness (CMT) After At Least I Year of Follow-Up for Eyes with Idiopathic Epiretinal Membranes (iERMs): Group I (VA $\geq 20 / 30$ ) and Group II (VA 20/40 - 20/ 50)

\begin{tabular}{|c|c|c|c|c|c|c|c|c|}
\hline \multirow{3}{*}{$\begin{array}{l}\text { Best-Corrected Visual Acuity (BCVA) } \\
\text { [logMAR (Mean } \pm \text { SD) and Snellen } \\
\text { Equivalent] }\end{array}$} & \multicolumn{4}{|c|}{ Group I [Baseline BCVA $\geq 20 / 30](n=136)$} & \multicolumn{4}{|c|}{$\begin{array}{l}\text { Group II [Baseline BCVA 20/40 - 20/50] } \\
(n=38)\end{array}$} \\
\hline & $\begin{array}{l}\text { Typical } \\
\text { ERM (108) }\end{array}$ & & $\begin{array}{l}\text { Lamellar } \\
\text { Macular } \\
\text { Hole (28) }\end{array}$ & & $\begin{array}{l}\text { Typical } \\
\text { ERM (3 I) }\end{array}$ & & $\begin{array}{l}\text { Lamellar } \\
\text { Macular } \\
\text { Hole (7) }\end{array}$ & \\
\hline & & p-Value & & p-Value & & p-Value & & p-Value \\
\hline - Baseline BCVA & $\begin{array}{l}0.09 \pm 0.1 \\
(20 / 25)\end{array}$ & \multirow[t]{2}{*}{0.22} & $\begin{array}{l}0.10 \pm 0.07 \\
(20 / 25)\end{array}$ & \multirow[t]{2}{*}{0.08} & $\begin{array}{l}0.3 \pm 0.05 \\
(20 / 44)\end{array}$ & \multirow[t]{2}{*}{0.31} & $\begin{array}{l}0.3 \pm 0.04 \\
(20 / 43)\end{array}$ & \multirow[t]{2}{*}{0.79} \\
\hline - Final BCVA & $\begin{array}{l}0.10 \pm 0.1 \\
(20 / 25)\end{array}$ & & $\begin{array}{l}0.2 \pm 0.1^{*} \\
(20 / 28)\end{array}$ & & $\begin{array}{l}0.4 \pm 0.2 \\
(20 / 45)\end{array}$ & & $\begin{array}{l}0.3 \pm 0.1 \\
(20 / 44)\end{array}$ & \\
\hline \multicolumn{9}{|c|}{ Central Macular Thickness $($ CMT in $\mu \mathrm{m}){ }^{* *}($ Mean \pm SD) } \\
\hline - Baseline CMT & $335 \pm 73$ & \multirow[t]{2}{*}{0.47} & $345 \pm 73$ & \multirow[t]{2}{*}{0.94} & $386 \pm 95$ & \multirow[t]{2}{*}{0.84} & $350 \pm 103$ & \multirow[t]{2}{*}{0.75} \\
\hline - Final visit CMT & $342 \pm 78$ & & $344 \pm 71$ & & $391 \pm 93$ & & $339 \pm 92$ & \\
\hline Follow-Up (months) & $17.1 \pm 5.1$ & - & $18.2 \pm 4.7$ & 0.90 & $16.4 \pm 4.2$ & - & $18.1 \pm 5.7$ & 0.84 \\
\hline
\end{tabular}

Notes: *Cataract surgery or YAG laser capsulotomy (I4 eyes in Group I and 3 eyes in Group II) and cataract progression or posterior capsular opacity (17 eyes in Group I and 7 eyes in Group II); **CMT by SD-OCT; statistical analysis by Student's $t$-test. 
Table 2 Changes in the Recorded Visual Acuity and Central Macular Thickness (CMT) in Eyes with Idiopathic Epiretinal Membranes (iERMs) After At Least I Year of Follow-Up: Group I (BCVA $\geq 20 / 30$ ) and Group II (BCVA 20/40 - 20/50)

\begin{tabular}{|c|c|c|c|c|}
\hline \multirow[t]{2}{*}{ ERM Classification } & \multicolumn{2}{|c|}{ Group I [Baseline BCVA $\geq 20 / 30](n=136)$} & \multicolumn{2}{|c|}{ Group II [Baseline BCVA 20/40 - 20/50] $(n=38)$} \\
\hline & $\begin{array}{l}\text { Typical ERM ( } 108) \\
\text { [\%] }\end{array}$ & $\begin{array}{l}\text { Lamellar Macular Hole (28) } \\
\text { [\%] }\end{array}$ & $\begin{array}{l}\text { Typical ERM (3I) } \\
\text { [\%] }\end{array}$ & $\begin{array}{l}\text { Lamellar Macular Hole (7) } \\
\text { [\%] }\end{array}$ \\
\hline \multicolumn{5}{|c|}{ Visual Acuity $\S^{\S}$ Change From Baseline } \\
\hline $\begin{array}{l}\text { - Improved (>2 lines) } \\
\text { - Stable ( } \pm 1 \text { line) } \\
\text { - Worsened (>2 lines) }\end{array}$ & $\begin{array}{l}10[9.2] \\
89[82.4] \\
9[8.3]\end{array}$ & $\begin{array}{l}\text { I }[3.6] \\
2 \mid[75.0] \\
6[2 \mid .4]\end{array}$ & $\begin{array}{l}5[16.1] \\
22[70.9] \\
4[12.1]\end{array}$ & $\begin{array}{l}0 \\
6[85.7] \\
\text { I [14.3] }\end{array}$ \\
\hline \multicolumn{5}{|c|}{ Central Macular Thickness (CMT in $\mu \mathrm{m}) *$ Change From Baseline } \\
\hline $\begin{array}{l}\text { - Improved }(<30 \mu \mathrm{m}) \\
\text { - Stable }( \pm 30 \mu \mathrm{m}) \\
\text { - Worsened }(>30 \mu \mathrm{m})\end{array}$ & $\begin{array}{l}7[6.4] \\
85[78.7] \\
16[14.8]\end{array}$ & $\begin{array}{l}5[17.8] \\
23[82.1] \\
0\end{array}$ & $\begin{array}{l}4[12.9] \\
18[58.1] \\
9[29.0]\end{array}$ & $\begin{array}{l}\text { I [14.3] } \\
6[85.7] \\
0\end{array}$ \\
\hline
\end{tabular}

Notes: ${ }^{\S}$ Visual acuity as recorded in the medical record; *CMT by SD-OCT; P values of the VA changes between Groups I and II (Typical ERM, P $\left.=0.39 ; \mathrm{LMH}, \mathrm{P}=0.44\right)$ and CMT changes between Groups I and II (Typical ERM, $\mathrm{p}=0.17$; LMH, $\mathrm{p}=0.75$ ) by Kruskal-Wallis test.

For Group II LMHs, the logMAR baseline and final mean BCVA were $0.33 \pm 0.04(20 / 43)$ and $0.3 \pm 0.1(20 /$ 44) respectively $(\mathrm{p}=0.79)$. In this group, the baseline and final mean CMT mean were $350 \pm 103 \mu \mathrm{m}$ and $339 \pm$ $92 \mu \mathrm{m}$, respectively $(\mathrm{p}=0.75)$. In Group II LMHs, there was no statistically significant change in the BCVA and CMT at the final follow-up.

To summarize, there were no significant changes from baseline to the latest follow-up BCVA in any of the subgroups (Table 2). Furthermore, the great majority of patients also maintained their CMT within $30 \mu \mathrm{m}$ of baseline (Table 2).

\section{Discussion}

The current study results contest the premise of disease progression and document BCVA and anatomic stability in this group of patients with relatively good baseline BCVA and a lack of other compelling reasons (activity of daily living or disproportionate metamorphopsia) to operate at baseline. Patients with metamorphopsia and reduced visual acuity caused by iERMs are often considered for surgical intervention under the expectation of some improvement (not total resolution) of attributable visual symptoms. With the advent of improved vitrectomy instrumentation and lower complication rates, surgeons have generally lowered the BCVA threshold to consider vitrectomy for iERMs with better BCVA. The rationale for the lowering of the surgical threshold by some is the unproven assumption that iERMs have a tendency to progress to poorer BCVA with a high frequency. It has been stated that with continued observation for these patients, a window of opportunity may be lost to stabilize or improve vision.

Surgical intervention in patients with good baseline BCVA usually results in good postoperative visual acuity but improvements are only partial. In a series of 33 eyes with baseline VA of 20/50 or better who underwent PPV and membrane peel, the mean VA improved from 20/40 preoperatively to $20 / 30$ postoperatively. ${ }^{10}$ Improvement of visual symptoms was achieved in $73 \%$ (24 of 33) of patients. ${ }^{10}$ In another series of 40 eyes of 40 patients who underwent PPV for iERM, a mean preoperative BCVA of 20/50 and a mean postoperative BCVA of 20/ 40 was reported. ${ }^{5}$ Again, the mean gain in BCVA amounted to an average of 1 line following surgery, but no disproportionately better improvement in qualitative symptoms was documented. ${ }^{5,11}$

Surgical complications may have a significant impact on visual outcomes. The most frequent consequence of vitrectomy is cataract progression. ${ }^{4,10,12,13}$ Other potential retinal adverse events include retinal tears, retinal detachment, macular light toxicity, and endophthalmitis, among others. ${ }^{414}$ The small risk but serious impact of retinal detachment must especially be weighed when operating on patients with good baseline BCVA. In a retrospective study of Vaziri et al, patients who underwent pars plana vitrectomy for macular holes, the rate of retinal detachment was $3.9 \%$ to $5.7 \%$ after 12 months although other studies have reported lower rates closer to $1 \% .{ }^{15}$ While PPV for ERM is not identical to that for macular hole, the risk for retinal detachment during or after these surgeries must be considered similar. 
Several studies of iERM in patients with good BCVA failed to show a significant progression. The Blue Mountain Eye Study noted that of 3654 patients evaluated, less than $30 \%$ progressed (progression defined as cellophane macular reflex without retinal folds to preretinal macular fibrosis with retinal folds) while $26 \%$ regressed and $39 \%$ remained stable over a period of 5 years. ${ }^{11}$ In a smaller observational study of idiopathic preretinal gliosis by Sidd et al, final BCVA remained within one line of the first examination in 51/72 (71\%) eyes during a mean follow-up period of 31.1 months. ${ }^{16}$ In the current study, none of the patients had a statistically significant change ( \pm 1 line) in BCVA from baseline to final follow-up.

Furthermore, the reversal of photoreceptor damage may not be alleviated even by early surgery. In an interventional, prospective, randomized case series by Suh et al, photoreceptor disruption on OCT occurring presumably due to macular traction caused by iERM was reported to be a predictor of poor visual outcome. ${ }^{6}$ However, in the same series new photoreceptor disruption was noted in 8 of 12 eyes which underwent membrane peeling surgery. ${ }^{6}$ This raises the question of whether surgery prevents or actually causes photoreceptor disruption.

A purely mathematical constraint is that patients with good baseline BCVA have less measured BCVA to gain than those with poorer baseline BCVA, but the current study is not generalizable to those with iERMs and baseline BCVA worse than 20/50. In one study from 1986, it was noted that patients starting with poorer vision, eg worse than 20/100, gained significantly more lines of vision than those with better visual acuity. ${ }^{7}$ More recently in a series of 125 eyes, patients with preoperative logMAR BCVA of 1.0 (Snellen 20/200) on average gained nearly double the lines of BCVA as those with logMAR BCVA of $0.5(20 / 40) .{ }^{17}$ Thus, the risk-benefit analysis for patients with poorer baseline BCVA caused by iERMs seems to favor surgical intervention. The current study does not support the contention that those with relatively good vision are at a substantial risk of entering these subgroups with poor BCVA.

Spontaneous release of iERM with improvement in BCVA has been described in a small percentage of patients, but this is likely associated with spontaneous vitreous separation, and may even have represented cases in the spectrum of vitreomacular traction, as these reports predate the OCT era. Gass first reported the spontaneous improvement in iERMs in 1976 in eight patients with normal or near-normal initial BCVA. $^{1}$ While only a minority of patients $(<10 \%)$ with
iERM may expect spontaneous improvement in BCVA, this possibility must also be weighed against the risks of surgery. ${ }^{18-20}$

The current study has several limitations. First, the retrospective design of the study may lend itself to selection bias. The patients were identified for this study based on diagnosis, not by symptoms. The documentation of symptoms including metamorphopsia was inconsistent and, therefore, could not be meaningfully evaluated by the present study. This study may include patients whose iERMs were detected by OCT for another reason or by clinical exam in the absence of symptoms. Other limitations include the followup interval as well as the inclusion of fellow eyes.

Overall, these findings and the implied recommendation for considering restraint in offering surgery to the patient with good initial BCVA are consistent with the most current American Academy of Ophthalmology Preferred Practice Pattern (accessed July 2018), which notes that the majority of iERMs remain fairly stable, especially in short-term follow-up, and that often no therapy is needed (good quality, strong recommendation). ${ }^{4}$ The patient's symptom severity and limitations to activities of daily living may help guide the decision for surgical intervention. ${ }^{4}$

The clinical course of iERMs with initially good BCVA tends to have a stable BCVA and anatomical outcomes during one or more years of observational followup. Generally, better follow-up BCVA is associated with better baseline BCVA since there is little or no appreciable progression. It is important to consider the patient's visual acuity, symptoms, and expectations before undertaking a surgical procedure.

\section{Funding}

This study was partially supported by NIH Center Core Grand P30EY014801 and by an unrestricted grant from Research to Prevent Blindness to the University of Miami and the Heed Foundation.

\section{Disclosure}

The authors report no conflicts of interest in this work.

\section{References}

1. Allen AW Jr., Gass JD. Contraction of a perifoveal epiretinal membrane simulating a macular hole. Am J Ophthalmol. 1976;82 (5):684-691. doi:10.1016/0002-9394(76)90002-7

2. Aung KZ, Makeyeva G, Adams MK, et al. The prevalence and risk factors of epiretinal membranes: the Melbourne Collaborative Cohort Study. Retina. 2013;33(5):1026-1034. doi:10.1097/IAE.0b013e318 $2733 f 25$ 
3. $\mathrm{Ng} \mathrm{CH}$, Cheung $\mathrm{N}$, Wang JJ, et al. Prevalence and risk factors for epiretinal membranes in a multi-ethnic United States population. Ophthalmology. 2011;118(4):694-699. doi:10.1016/j.ophtha.2010.08.009

4. Folk JC, Adelman RA, Flaxel CJ, et al. Idiopathic epiretinal membrane and vitreomacular traction preferred practice pattern $((\mathrm{R}))$ guidelines. Ophthalmology. 2016;123(1):P152-P181. doi:10.1016/j. ophtha.2015.10.048

5. Thompson JT. Epiretinal membrane removal in eyes with good visual acuities. Retina. 2005;25(7):875-882. doi:10.1097/00006982200510000-00010

6. Suh MH, Seo JM, Park KH, Yu HG. Associations between macular findings by optical coherence tomography and visual outcomes after epiretinal membrane removal. Am J Ophthalmol. 2009;147(3):47380.e3. doi:10.1016/j.ajo.2008.09.020

7. Rice TA, De Bustros S, Michels RG, et al. Prognostic factors in vitrectomy for epiretinal membranes of the macula. Ophthalmology. 1986;93(5):602-610. doi:10.1016/S0161-6420(86)33689-3

8. Lum F, Feder RS, McLeod SD, Parke DW 2nd. The preferred practice pattern guidelines in ophthalmology. Ophthalmology. 2016;123(5):928-929. doi:10.1016/j.ophtha.2016.01.024

9. Haouchine B, Massin P, Tadayoni R, et al. Diagnosis of macular pseudoholes and lamellar macular holes by optical coherence tomography. Am J Ophthalmol. 2004;138(5):732-739. doi:10.1016/ j.ajo.2004.06.088

10. Lehpamer BP, Carvounis PE. Pars plana vitrectomy for symptomatic epiretinal membranes in eyes with $20 / 50$ or better preoperative visual acuity. Retina. 2015;35(9):1822-1827. doi:10.1097/IAE.00000000000 00541

11. Fraser-Bell S, Guzowski M, Rochtchina E, et al. Five-year cumulative incidence and progression of epiretinal membranes: the blue mountains eye study. Ophthalmology. 2003;110(1):34-40. doi:10.10 16/S0161-6420(02)01443-4
12. Falkner-Radler CI, Glittenberg C, Hagen S, et al. Spectral-domain optical coherence tomography for monitoring epiretinal membrane surgery. Ophthalmology. 2010;117(4):798-805. doi:10.1016/j.ophtha. 2009.08.034

13. Kim J, Rhee KM, Woo SJ, et al. Long-term temporal changes of macular thickness and visual outcome after vitrectomy for idiopathic epiretinal membrane. Am J Ophthalmol. 2010;150(5):701-9.e1. doi:10.1016/j.ajo.2010.05.037

14. Parke DW 3rd, Lum F. Return to the operating room after macular surgery: IRIS registry analysis. Ophthalmology. 2018;125(8):12731278. doi:10.1016/j.ophtha.2018.01.009

15. Vaziri K, Schwartz SG, Kishor KS, et al. Rates of reoperation and retinal detachment after macular hole surgery. Ophthalmology. 2016;123(1):26-31. doi:10.1016/j.ophtha.2015.09.015

16. Sidd RJ, Fine SL, Owens SL, Patz A. Idiopathic preretinal gliosis. Am J Ophthalmol. 1982;94(1):44-48. doi:10.1016/0002-9394(82) 90189-1

17. Wong JG, Sachdev N, Beaumont PE, Chang AA. Visual outcomes following vitrectomy and peeling of epiretinal membrane. Clin Exp Ophthalmol. 2005;33(4):373-378. doi:10.1111/ceo.2005.33.issue-4

18. Greven CM, Slusher MM, Czyz CN. The natural history of macular pseudoholes. Am J Ophthalmol. 1998;125(3):360-366. doi:10.1016/ S0002-9394(99)80147-0

19. Michalewska Z, Michalewski J, Odrobina D, Nawrocki J. Non-fullthickness macular holes reassessed with spectral domain optical coherence tomography. Retina. 2012;32(5):922-929. doi:10.1097/ IAE.0b013e318227a9ef

20. Walter SD, Flynn HW Jr. Spectral domain optical coherence tomography documentation of macular pseudohole evolution and spontaneous resolution. Retin Cases Brief Rep. 2016;10(4):377-381. doi:10.1097/ICB.0000000000000268
Clinical Ophthalmology

\section{Publish your work in this journal}

Clinical Ophthalmology is an international, peer-reviewed journal covering all subspecialties within ophthalmology. Key topics include: Optometry; Visual science; Pharmacology and drug therapy in eye diseases; Basic Sciences; Primary and Secondary eye care; Patient Safety and Quality of Care Improvements. This journal is indexed on PubMed

\section{Dovepress}

Central and CAS, and is the official journal of The Society of Clinical Ophthalmology (SCO). The manuscript management system is completely online and includes a very quick and fair peer-review system, which is all easy to use. Visit http://www.dovepress.com/ testimonials.php to read real quotes from published authors. 